\title{
PRINCIPALES FACTORES TRANVERSALES DE INSEGURIDAD ECONÓMICO-SOCIAL EN MELILLA CON ORIGEN EN EL ENTORNO NORTEAFRICANO
}

\author{
JESÚS A. GARCÍA AYALA \\ Doctor en Ciencia Política y de la Administración por la Universidad de Granada \\ Licenciado en Ciencias Económicas y Empresariales por la \\ Universidad Complutense de Madrid
}

\begin{abstract}
Resumen: Al principal factor de inseguridad que afecta a la ciudad de Melilla: las episódicas demandas territoriales de Marruecos, se añaden otros tanto específicos como horizontales. Estos últimos factores, al afectar por definición a todos los demás, conforman una envolvente de inseguridades, amenazas y riesgos que, por su importancia en general y socioeconómica en especial, merece ser analizada. En consecuencia, se procede a estudiar los cinco factores transversales de riesgo que se consideran más importantes: el contencioso internacional del Sahara Occidental, la pesca española en caladeros marroquíes, el tráfico ilegal de drogas tóxicas y estupefacientes, la inmigración clandestina y el auge del islamismo radical violento. En lo que hubiera sido un análisis adecuado hasta la reciente "Revolución de los jazmines en Túnez", se integra ahora la variable, aún poco conocida, de la repercusión de dicho movimiento social a través de Marruecos esencialmente.
\end{abstract}

Palabras clave: Acuerdo pesquero con Marruecos, hachís, inmigración clandestina, inmigración ilegal, islamismo radical, Marruecos, Melilla, Sahara Occidental, terrorismo islámico.

Clasificación JEL: F22, F51, F53, F55, I38, K33, L72, N57, N77, O13, O15, Q22, Q32, Q33.

\begin{abstract}
To the main factor of insecurity that affects the city of Melilla: the sporadic territorial demands of Morocco, add other specific and horizontal ones. These last factors, when affecting by definition to all the others, conform a set of insecurities, threats and risks that, by their importance in general and socioeconomic in special, deserve to be analyzed. Consequently, it is come to study the five crosssectional factors of risk that are considered more important: the international contentious of the Western Sahara, the Spanish fishing in Moroccan fishing-grounds, the illegal traffic of toxic drug and narcotic, the clandestine immigration and the height of the violent Islamic fundamentalism. In which it had been an adequate analysis until the recent

"Revolution of jasmines in Tunisia", the variable of the repercussion of this social movement through Morocco essentially, still little well-known, is included now.
\end{abstract}

Key words: Clandestine immigration, fishing agreement with Morocco, hashish, illegal immigration, Islamic fundamentalism, Islamic terrorism, Melilla, Morocco, Western Sahara. 


\section{INTRODUCCIÓN}

El principal y singular factor de inseguridad que padece la ciudad española de Melilla está constituido por las episódicas demandas ${ }^{1}$ de Marruecos para que dicha ciudad le sea entregada, sobre la base de los supuestos títulos de soberanía que afirma le asisten. ${ }^{2}$ Dicha demanda se reproduce asimismo sobre los demás territorios de soberanía española en el litoral norte africano limítrofe con Marruecos. Se trata, de Este a Oeste, de los siguientes: Islas Chafarinas (Al-jaafarinas), Melilla (Mlilya), Isla de Alborán (Al-Borany), Isla de Mar e Isla de Tierra, Peñón de Alhucemas (Nkour), Peñón de Vélez de la Gomera (Badis), Ceuta (Sebta) e Islote Perejil (Leila o Laila y Toura o Tura). ${ }^{3}$

Habida cuenta que estas demandas se vienen repitiendo intermitentemente desde 1960 æcuatro años después de la independencia de Marruecosæ y considerado el historial de contenciosos, e incluso conflictos armados abiertos entre España y dicho país, ${ }^{4}$ las mismas vienen a constituir un indudable factor de inseguridad para Melilla en varios ámbitos. Entre ellos está sin duda el de las decisiones de los inversores privados, y por ende el de la sostenibilidad y desarrollo económico de la ciudad en el plano civil a medio y largo plazo; paralelamente el de la estabilidad, arraigo y crecimiento de la población española residente. En definitiva, las citadas demandas constituyen un indudable elemento perturbador para la seguridad económica y social de Melilla, que se mueve entre dos tendencias contrapuestas: por una parte la de su empeoramiento, si nos atenemos a la experiencia histórica de desencuentros entre España y Marruecos, y por otra parte la de su mejora, si atendemos a la prospectiva futura de los intereses mutuos asumidos como países aliados bilateral y multilateralmente.

${ }^{1}$ En el aspecto terminológico participamos del criterio de LÓPEZ BUENO, J. M. (2008) acerca de que, mientras el término "reclamación" incluye implícitamente la existencia de derechos a favor del demandante, el término "demanda" no lo hace, por lo que en el caso de las frecuentemente denominadas "reclamaciones" o "reivindicaciones" de Marruecos sobre Melilla y Ceuta resulta más apropiado utilizar la denominación de "demandas", habida cuenta que Marruecos no dispone de documentos bastantes para justificar las mismas.

${ }^{2}$ Puede consultarse al respecto la tesis doctoral del autor: "Las políticas de la Unión Europea en Melilla (1986-2008): Valoración de sus efectos, prospectiva y decisiones estratégicas para su optimización desde una perspectiva de seguridad económica y social" (2009); disponible en web: <http://hera.ugr.es/tesisugr/ 18604985.pdf>. Págs. 129 y 793-801.

${ }^{3}$ Ibídem (págs. 124-138).

${ }^{4}$ Las guerras entre España y Marruecos en este contexto han sido las denominadas: Guerra de África, Guerra de Melilla, Guerra del Rif y Guerra de Ifni; ésta, finalizada en 1958, fue la última. Aparte están la situación prebélica en el Sahara Español en 1975 y 1976, y el incidente armado en la isla Perejil en 2002. 
Según el Instituto Heidelberg para la Investigación de los Conflictos Internacionales, el contencioso entre España y Marruecos por la demanda territorial marroquí de Melilla y Ceuta es uno de los cinco que afectan a España en la actualidad. ${ }^{5}$ El contencioso "Marruecos vs. España" sobre las ciudades de Melilla y Ceuta es descrito por dicho instituto como una disputa territorial planteada en 1956, calificado de nivel 1 (conflicto latente) y con un nivel de intensidad sin variación entre 2008 y 2010, después de que en 2007 se situara en un peldaño más alto al ser calificado de nivel 2 (conflicto manifiesto).

La seguridad de Melilla afectada, tanto potencial como realmente, por las demandas marroquíes citadas estimamos que puede dividirse, desde un enfoque analítico, en varias tipologías concurrentes e interrelacionadas. Son identificables al efecto, además de la económico-social (diferencias esenciales, interdependencias y dependencias bilaterales y estrategias de desarrollo regional), la de orden territorial (superficie terrestre, aguas jurisdiccionales y espacio aéreo) y la militar (capacidades bélicas, alianzas internacionales y otras variables diversas).

En el presente trabajo vamos a limitarnos, empero, a la consideración de cinco factores de carácter transversal, es decir, susceptibles de afectar a todas las tipologías. Estos factores son: a) Contencioso internacional del Sahara Occidental; b) Pesca española en caladeros marroquíes; c) Tráfico ilegal de drogas tóxicas y estupefacientes; d) Inmigración clandestina; e) Auge del islamismo radical violento. En cuanto al último factor generador de inseguridad sobrevenido recientemente: la revolución tunecina de los jazmines y los efectos que puede producir en Melilla, fundamentalmente a través de su impacto en Marruecos, su tratamiento específico se reserva para un trabajo ad hoc; empero, ello no ha impedido que se haya tenido en cuenta en el análisis de cada uno de los cinco factores horizontales contemplados.

\section{Precisión de los objetivos del presente trabajo:}

El objetivo final es la identificación de las amenazas y elementos de riesgo que, para la seguridad económica y social de Melilla, surgen de cada uno de los cinco factores horizontales abordados.

Por su parte, el objetivo intermedio es el análisis del estado de situación actual de cada uno de dichos factores, lo que ha incluido la identificación de los intereses concurrentes en cada caso y de los actores involucrados en función de aquellos.

\footnotetext{
${ }^{5}$ Los otros cuatro que cita son: ETA, Gibraltar, Cataluña e Isla de Perejil. A ellos habría de añadirse el referido a Olivenza (citado por la CIA)
} 


\section{Importancia para los intereses españoles:}

El análisis efectuado resulta de interés directo para España y, en particular, para Melilla, habida cuenta que el objeto de la inseguridad analizada es esta misma ciudad, la cual resulta potencialmente afectada en diversos órdenes, entre ellos el económico y el social. No debe olvidarse que puede estar en juego su propia supervivencia en los términos económicos, sociales e internacionales actuales.

Por otra parte, los intereses citados están asociados principalmente a la conveniencia de, a partir de un análisis de riesgos, poder adoptar las medidas preventivas que se consideren oportunas, tanto desde una perspectiva reactiva como, especialmente, proactiva.

En efecto, por una parte debe contarse con acciones de reacción contra eventuales escenarios negativos desde la perspectiva de la seguridad; y por otro lado deben implementarse medidas proactivas o anticipatorias de un eventual futuro negativo, predisponiendo este hacia un escenario positivo para Melilla, o lo que es lo mismo, ocupándose de construir un futuro deseable.

\section{Estructuración del artículo:}

La sistemática a seguir es similar para todos y cada uno de los cinco factores de riesgo analizados.

En primer lugar, se procede a establecer el estado de situación de cada uno de ellos, sobre la base de los actores, hechos y características más relevantes desde una perspectiva de seguridad económica y social, teniendo presente que se trata de conocer el pasado y el presente para, sobre tal base, poder abordar con rigor la prospectiva sobre alternativas de futuro.

En segundo lugar se procede a identificar, así como a conocer el contenido correspondiente, de los efectos de inseguridad que las amenazas y riesgos estudiados pueden originar sobre la ciudad de Melilla en un futuro próximo.

Finalmente se aportan determinadas conclusiones, con vocación de ser útiles para la elaboración de acciones reactivas y proactivas contra los posibles efectos negativos detectados.

\section{Revisión de la literatura científica:}

En la literatura de interés para el estudio de los factores de inseguridad a que se refiere el presente trabajo cabe diferenciar tres etapas.

La primera llega hasta el 11-S 2001, fecha de los tristemente célebres atentados terroristas contra las torres gemelas de Nueva York; hasta dicha fecha la literatura trataba 
lo relativo a los factores de inseguridad en un marco multidisciplinar, en el que si hubiera que destacar algo sería el equilibrio entre disciplinas. Entre los autores de mayor relevancia en el contexto al que se refiere el presente trabajo cabe citar a Lazrak (1974), Hajjaji (1986), Escribano (1997-1998), Lorca (1997-1998), Marín (1998), Gold (1999), Morales Lezcano (2000), De la Serna (2001), Delmote (2001) y Núñez Villaverde (2001).

La segunda etapa comienza en 2002, una vez que tras los atentados citados se introduce en la literatura científica de referencia, con una elevada frecuencia, la cuestión del fundamentalismo islámico de carácter violento y terrorista; en este marco los autores que cabe destacar son Escribano (2002), Jerch (2002), Lorca (2002), Soddu (2002), Aziza (2003-2006), Ben Yahia (2003), Hernando de Larramendi (2003-2004), Lacleta Muñoz (2003-2004), Moré (2003), Planet (2003), Jordan Galduf (2004), Kachani (2004), Pérez González (2004-2008), Ruiz Miguel (2004), Echeverría Jesús (2005), Fibla (2005), López García (2005-2010), Pérez (2005), Reinares (2005), Ribas-Mateos (2005), Szmolka Vida (2005), Zurlo (2005), Cembrero Silvero (2006), Ferrer-Gallardo (2006-2010), Torrejón (2006), Zeghal (2006), Avilés (2008), González Enríquez (2008), Joly (2008), AmirahFernández (2009), Marmolejo Martín (2009), Arahuetes (2010), Bujari (2010), Lmrabet (2010), López Bueno (2010), Papademetriou (2010) y Steinberg (2010).

La tercera etapa es la iniciada a partir del 17-D 2010, en tanto fecha aceptada con carácter general como de la "Revolución de los jazmines en Túnez". Su singularidad radica en que a partir de la fecha citada la literatura sobre aspectos políticos, económicos y sociales, entre otros, relativos al norte de África y al mundo árabe e islámico en general se hace eco de los fenómenos sociales iniciados enTúnez y reproducidos, con determinadas variaciones, en otros países del entorno político, social, cultural y religioso. Los autores más destacables por abordar en dicho contexto cuestiones relacionadas con los factores objeto del presente trabajo son Amirah-Fernández, Arias, Benantar, Capella Soler, Cembrero Silvero, González Enríquez, Hernando de Larramendi, Kirhlani, López García, Reinares y Tortosa.

Por otra parte son de destacar también las aportaciones de Europol y Frontex, instituciones de la UE entre cuyos cometidos figuran los análisis del tráfico ilegal internacional de drogas tóxicas y estupefacientes, y del terrorismo islámico, en el primer caso, y en ambos el análisis de la inmigración clandestina originaria o procedente de países terceros. ${ }^{6}$ Finalmente debe hacerse mención a la Comunicación de la Comisión Europea denominada "Plan de política en materia de migración legal" (COM(2005) 669 final).

\footnotetext{
${ }^{6}$ En cuanto a la instrumentación de las aportaciones científicas más allá de la esporádica mediante libros, debe mencionarse la más ágil de las diferentes publicaciones especializadas, tanto por ámbito geográfico como
} 


\section{CONTENCIOSO INTERNACIONAL DEL SAHARA OCCIDENTAL}

Dada su internacionalización y la multiplicidad de actores involucrados, parece apropiado dividir su examen en dos apartados: por una parte actores e intereses a los que afecta, y por otro lado las amenazas propiamente dichas que comporta para la seguridad de Melilla.

\subsection{Actores e intereses afectados}

Destacan los siguientes:

- ARGELIA. Desde un punto de vista geoestratégico prefiere un Estado saharaui independiente, aliado contra el expansionismo marroquí, ante el riesgo de la demanda por Marruecos de sus supuestos derechos sobre el Sahara argelino. En este contexto, que implica diferencias con la posición española actual, se sitúa su condición de principal exportador de gas a España.

- EE UU. Se mueve dentro de un complejo entramado de intereses, algunos contrapuestos. Desde una perspectiva estratégica, el Sahara Occidental es fundamental para la influencia americana en el África atlántica, a través precisamente de un Estado aliado: Marruecos, que es asimismo un elemento clave para controlar el acceso al Mediterráneo; además, no es acorde a sus intereses que la RASD ${ }^{7}$ se convierta en un nuevo Estado, dado que ello supondría un riesgo para la estabilidad de la zona e implicaría una alianza con Argelia. Desde una perspectiva económica, por una parte tampoco es del

temático. En España destacan tres títulos: Foreign Policy Edición española, Política Exterior y Vanguardia Dossier. Además, no puede omitirse la importancia de los laboratorios de ideas (think tanks) en su función de constituir "el puente entre el conocimiento y el poder" (definición del Programa de las Naciones Unidas para el Desarrollo); entre los reputados como independientes destacan: Casa Árabe (Instituto Internacional de Estudios Árabes y del Mundo Musulmán), Cidob (Centro de Estudios y Documentación Internacionales de Barcelona), Euromed (Fundación para el Diálogo), EuroMeSCo (Euro-Mediterranean Study Comisión), European Council (Consejo europeo), ICEI (Instituto Complutense de Estudios Internacionales), Iecah (Instituto de Estudios sobre Conflictos y Acción Humanitaria), IEMed (Instituto Europeo del Mediterráneo), Incipe (Instituto de Cuestiones Internacionales y Política Exterior), Foreign Relations (Relaciones extranjeras), Fride (Fundación para las Relaciones Internacionales y el Diálogo Exterior), el creado en 2001 y considerado hoy como de referencia en España denominado Real Instituto Elcano, y TEIM (Taller de Estudios Internacionales Mediterráneos). También resulta de importancia la contribución, a pesar de que ponen más énfasis en la acción que en el estudio, de organizaciones españolas como, entre otras, el Centro de Toledo para la Paz y el Club de Madrid.

\footnotetext{
${ }^{7}$ República Árabe Saharaui Democrática.
} 
interés de EE UU que Marruecos se convierta en un gran competidor en el mercado mundial de los fosfatos, mientras que por otro lado sí resulta de su interés beneficiarse de cooperación sobre el uranio, el petróleo y los demás recursos naturales existentes tanto en el Sahara Occidental como en Marruecos. Simultáneamente, EE UU mantiene fuertes intereses económicos con Argelia, tanto en materia de comercio de gas como en inversiones en la industria del petróleo.

- ESPAÑA. La actual posición del Gobierno español se percibe como de abandono de la que se consideraba coherente con la celebración de un referéndum acerca de la autodeterminación del pueblo saharaui, lo que viene a coincidir con la postura de Marruecos, apoyada a su vez por Francia. Cabe deducir que priman las relaciones e intereses con Marruecos y la prevención manifestada sobre una desestabilización de todo el Magreb como consecuencia probable del citado referéndum.

- FRANCIA. En 1975 contaba con amplios intereses estratégicos y económicos en la zona, coherentes con su apoyo a una anexión del Sahara por Marruecos y con su prevención contra la creación de micro-Estados que comportaran un riesgo de balcanización del Magreb. En una segunda etapa (iniciada en 1979) defendía que el problema era de descolonización y que lo procedente para resolverlo era el recurso al derecho de autodeterminación de los saharauis. En la actualidad Francia es una firme defensora de los últimos criterios de Marruecos, lo que es importante por, entre otras razones, su condición de miembro permanente del Consejo de Seguridad de la ONU.

- LIBIA. Desde los inicios tomó partido por la causa saharaui, en el marco de un posicionamiento en contra del neocolonialismo europeo, entendido tanto por la presencia previa española en el Sahara Occidental como por la última intervención de Francia en Mauritania. Inicialmente suministró armas y cobertura diplomática al Frente Polisario, postura que cambió a raíz de la firma con Marruecos del Tratado de Uxda para la constitución de la Unión Árabe Africana. En 1986 cambió nuevamente de criterio y se acercó a las tesis de Argelia, momento desde el que defiende activamente una visión panarabista que permita alcanzar la nación árabe-musulmana. Empero, a raíz del contagio de las revueltas iniciadas en Túnez la evolución es una incógnita.

- MARRUECOS. Tras oponerse a la vía del referéndum auspiciado por la ONU dentro del Plan Baker II, oferta como alternativa una amplia autonomía inscrita en un futuro proyecto de regionalización del reino. Todo ello dentro de un marco conformado por cuestiones tales como: la desautorización por el Tribunal de La Haya de que el Sahara Occidental estuviera bajo soberanía marroquí o mauritana cuando se produjo su colonización por España, el expansionismo geográfico marroquí por parte de la dinastía 
alauita, y los fosfatos y la pesca que constituyen los principales recursos naturales del Sahara Occidental (Marruecos ya es de por sí el mayor exportador mundial de fosfatos). ${ }^{8}$

-MAURITANIA. Tras una actitud inicial favorable a la reivindicación de anexionarse el antiguo Sahara español, el apoyo del partido Movimiento Nacional Democrático al independentismo saharaui no pudo resistir su propagación al ámbito armado. Ello por los ataques en las zonas de extracción de minerales y fosfatos que constituían la principal fuente de riqueza mauritana, en el contexto de una débil economía. En 1984, bajo el telón de fondo de un prolongado entendimiento con el Frente Polisario, reconoció a la RASD.

- ONU. Apoya el proceso de negociaciones a que se refieren las numerosas resoluciones aprobadas al efecto por el Consejo de Seguridad; entre ellas: 1754 (2007), 1783 (2007), 1813 (2008) y 1871 (2009). Sin embargo, la gestión del actual secretario general, Ban Ki-moon está siendo cuando menos controvertida; varias delegaciones le acusan de sesgo a favor de Francia y Marruecos. Por otra parte, las reuniones bilaterales y multilaterales que se vienen celebrando entre las partes más directamente afectadas siguen sin fructificar. ${ }^{9}$

- RASD Y FRENTE POLISARIO. No aceptan la alternativa de la autonomía propuesta por Marruecos e insisten en la vía del referéndum. No obstante, el Polisario está participando en sucesivas reuniones con Marruecos que, auspiciadas por la ONU, intentan alcanzar un acuerdo que desbloquee la situación actual.

-TÚNEZ. Poco afectado por este diferendo, se ha considerado un país neutral. En la práctica se ha venido posicionando ininterrumpidamente junto a las tesis marroquíes, ante la percepción de que un Estado saharaui constituiría un foco de inestabilidad en el Magreb. No obstante, el cambio de Gobierno como consecuencia de la revolución de los jazmines introduce incertidumbre.

${ }^{8}$ The World Factbook (2011) - Central Intelligence Agency (CIA).

${ }^{9}$ El proceso continúa sin perspectivas de alcanzar un acuerdo definitivo. Cabe destacar al respecto: Marruecos y el Frente Polisario celebraron tres reuniones directas en la localidad neoyorquina de Manhasset los días 18 y 19 de junio, 10 y 11 de agosto de 2007 y marzo de 2008. Habrían celebrado asimismo otra ronda, al menos, en la localidad suiza de Ginebra a finales de diciembre de 2007. Tras el estancamiento de las reuniones formales en 2008, celebraron una informal en Viena en 2009 y otra en Armonk, a unos 50 kilómetros al norte de Manhattan, el 10 y 11 de febrero de 2010, para discutir la convocatoria de una quinta ronda de negociaciones; participaron, además de Marruecos, delegaciones de Argelia, Mauritania y Frente Polisario. La siguiente reunión se celebró en la localidad neoyorquina de Manhasset, los días 8 y 9 de noviembre de 2010. En ninguna de todas estas reuniones se han conseguido alcanzar los acuerdos buscados. 
- OTROS ACTORES INTERNACIONALES. Los principales, en cuyos intereses y posiciones respectivos no vamos a detenernos, son los siguientes: Liga Árabe, Organización de la Unidad Africana (OUA), Países No Alineados, Parlamento Europeo, Rusia (en tanto potencia que seguiría detentando los intereses geoestratégicos, incluidos los económicos, de la extinta URSS), y Unión por el Magreb Árabe (UMA). Ostentan también intereses en la zona las grandes empresas estadounidenses productoras de fosfatos, los países con grandes intereses pesqueros (especialmente Corea del Sur), y empresas de prospección y explotación de petróleo con intereses en la plataforma marítima continental del Sahara Occidental. ${ }^{10}$ Por último, no habría que olvidar a China dados sus progresivos intereses en África.

\subsection{Amenazas para Melilla}

Este diferendo comporta amenazas para la seguridad de Melilla que pueden diferenciarse desde dos perspectivas: una es la del corto y medio plazo, y la otra la del largo plazo:

- La primera pivota sobre la necesidad que tiene Marruecos de la conformidad española a sus propuestas de solución de este diferendo, habida cuenta que España, en tanto antigua potencia administradora (que incluso lo podría seguir siendo de iure en la actualidad) ${ }^{11}$ es un actor clave en la solución del contencioso sobre el Sahara Occidental. Esta necesidad es determinante de que Marruecos podría utilizar como elemento de presión para lograr la conformidad de España (como la experiencia histórica avala), una escalada en sus demandas sobre Melilla y los demás territorios españoles en el norte de África. Sin embargo y dada la multiplicidad de actores e intereses involucrados en la solución del diferendo, no parece que España necesitara de las citadas presiones marroquíes para sumarse a una solución del mismo en términos de consenso con el resto de actores principales involucrados.

${ }^{10}$ Según un comunicado de la Oficina Nacional de Hidrocarburos y Minas (ONHYM) de Marruecos, en junio de 2009 se alcanzaban los 23 contratos suscritos, con 38 permisos de prospección, sobre una superficie total afectada de $262.030 \mathrm{~km} 2$.

${ }^{11}$ La declaración política contenida en los "Acuerdos de Madrid" suscritos entre España, Marruecos y Mauritania el 14 de noviembre de 1975 estipula que España transferirá la administración del Sáhara Occidental (no la soberanía), a una administración temporal tripartita compuesta por España, Marruecos y Mauritania; pero su validez ha sido cuestionada por la Secretaria General Adjunta de la ONU para Asuntos Jurídicos mediante dictamen de 29 de enero de 2002 (documento S/2002/161) 
- La segunda perspectiva, la del largo plazo, se refiere al momento en que dicho contencioso alcance, en su caso, una solución positiva para Marruecos, momento a partir del cual el siguiente paso en la histórica estrategia expansionista alauita podría constituirlo una reactivación de las demandas sobre los citados territorios españoles, hasta ahora no especialmente virulentas.

\section{PESCA ESPAÑOLA EN CALADEROS MARROQUÍES}

La situación de fondo es conocida: mientras Marruecos dispone de amplios caladeros de pesca sin una paralela capacidad cuantitativa ni técnica de su flota pesquera, España no dispone de caladeros propios suficientes y cuenta con una flota pesquera de grandes dimensiones, tanto en barcos como en personal, que cuenta además con un excelente nivel técnico. Por ello, ambos países pueden beneficiarse, en principio, de acuerdos reguladores al efecto. Veamos sucintamente las tres etapas más recientes, desde el ingreso de España en las CC EE, en cuanto al historial de acuerdos y desacuerdos entre ambos países y a sus principales repercusiones.

\subsection{Acuerdos entre 1995 y 2007}

El primer acuerdo de pesca celebrado entre la UE y Marruecos data de 1995 y fue firmado para una vigencia de cuatro años. El principal país comunitario beneficiado era España, dada la capacidad cuantitativa y técnica de su flota pesquera, como ya se ha indicado, dentro de un largo historial de acuerdos bilaterales al efecto España-Marruecos.

En 1999 las partes no llegaron a un acuerdo para renovar el Protocolo de 1995, por lo que al no ser éste automáticamente prorrogable decayó. Cabe resaltar aquí la reacción expresada por el presidente del Gobierno español Sr. Aznar, quien afirmó que el rechazo marroquí a suscribir un acuerdo pesquero no podría dejar de tener consecuencias. En definitiva, la negativa marroquí a suscribir un nuevo acuerdo de pesca con España (a través de la UE) fue el detonante de una etapa de tensiones España-Marruecos, adicionales a las experimentadas en otros órdenes (Sahara, etc.) y que tuvo evidentes repercusiones en el nivel de las demandas marroquíes sobre Melilla y Ceuta.

Hubo que esperar hasta 2005 para que se adquiriera el compromiso de un nuevo Acuerdo de Asociación en el Sector Pesquero entre la UE y Marruecos. Ratificado en 2007, destacan las siguientes características: a) Su vigencia es de 4 años prorrogables 
(28.02.2007 a 27.02.2011); b) Permite faenar en aguas de Marruecos y del Sahara Occidental a los buques de España y otros diez Estados miembros de la UE; c) La flota comunitaria recibe 119 licencias y permiso para capturar $60.000 \mathrm{tm}$ de pequeños pelágicos al año, de lo cual la flota española se queda al menos con 100 licencias ${ }^{12}$ y una asignación de $1.333 \mathrm{tm} ; ;^{13}$ d) La contrapartida financiera para Marruecos es de 144,4 millones de euros para los cuatro años, a los que se añaden otros' 3,0 como ayuda directa al sector marroquí y 3,4 por cuenta de los armadores.

\subsection{Confluencia con el diferendo del Sahara Occidental}

El Servicio legal del Parlamento Europeo ha criticado, en un informe realizado en 2010, el acuerdo de pesca entre la UE y Marruecos; lo considera problemático (aunque no ilegal). Este informe llama la atención sobre: a) La existencia de cierta ambigüedad en la delimitación de los caladeros atlánticos afectados por el acuerdo, situados entre las costas de Marruecos y del Sahara Occidental (mientras que, paradójicamente, en el caso de las aguas mediterráneas sí se aporta una definición aceptable); b) Tras constatarse que las flotas pesqueras han faenado en las aguas en torno al Sahara Occidental, cabe concluir que el acuerdo no ha tenido incidencia en la preceptiva traslación de beneficios a la población saharaui, ya que Marruecos no ha justificado el destino a favor de la misma de una parte de la dotación económica que recibe de la UE; c) En consecuencia el acuerdo, al no beneficiar a la población del Sahara adecuadamente (la sola mejora de los puertos resulta insuficiente a estos efectos), no respeta las leyes internacionales.

Poco antes de la expiración del acuerdo pesquero el 27.02.2011, la comisaria europea de pesca, María Damanaki, solicitó al Gobierno de Rabat información sobre la repercusión económica y social que estaba teniendo en la población del Sahara Occidental. Entre los Estados miembros, el Reino Unido, Suecia y Dinamarca activamente (votos en contra de la prórroga) y Alemania y Finlandia pasivamente (abstenciones) han venido defendiendo la necesidad de disponer de una información que demuestre, de un modo claro y suficiente, que el pueblo saharaui se está beneficiando del acuerdo. A juicio de la Comisión Europea la información finalmente aportada por Marruecos (en el cuarto año del acuerdo) demuestra el citado beneficio, si bien este criterio no es compartido por todos.

\footnotetext{
${ }^{12}$ Distribuidas así: 42 Andalucía, 37 Canarias, 17 Galicia, 2 Cantabria y 2 País Vasco.

${ }^{13}$ Lo que beneficia principalmente a pescadores de Andalucía e Islas Canarias.
} 
Como ejemplo de disidencia, la ONG británica "Western Sahara Resource Watch (WSRW)" y otras han tachado de inmoral el convenio por permitir que la flota comunitaria faene en aguas que no corresponden a Marruecos sino al Sahara Occidental; por dicha razón piden que se retiren de la zona los barcos que faenan enarbolando pabellón de cualquiera de los Estados miembros de la UE afectados. Debe recordarse en este contexto que los servicios jurídicos del Parlamento Europeo identificaban otras dos opciones (la acabada de citar la calificaban como no realista desde una perspectiva industrial): la interrupción del acuerdo, o la continuidad de este supeditando su prórroga al previo encuentro de una solución al problema.

\subsection{Amenazas para Melilla}

El 25 de febrero de 2011 la Comisión Europea y el Gobierno de Rabat alcanzaron un compromiso para la prórroga del acuerdo vigente por un período de año y medio. Salvo que no se consiga la preceptiva ratificación por el Consejo y el Parlamento europeos (el anterior acuerdo fue ratificado en 2007 a partir de un compromiso de 2005), hasta septiembre de 2012 queda aplazado el riesgo de tensiones España-Marruecos por motivo de la pesca. Aplazado pero no resuelto, dada la reiterada postura crítica de los Estados miembros de la UE y de las ONG antes mencionados y, entre algunas otras, la del autor de un dictamen de la ONU sobre estos aspectos, que defiende que es absurdo que sea Marruecos quien demuestre el beneficio del acuerdo para una población que ha anexionado ilegalmente, cuando debe ser dicha población quien sea consultada directamente de conformidad al derecho internacional.

En consecuencia, los 18 meses de prórroga a partir de febrero de 2011 no permiten desechar la reaparición de tensiones políticas. En el medio plazo tales tensiones pueden ser instrumentadas por Marruecos, una vez más, como un elemento de presión sobre España mediante la reactivación de sus demandas sobre Melilla y Ceuta. A largo plazo, empero, la solución no parece que pueda encontrarse fuera de una reducción drástica de la dependencia española de los caladeros de pesca marroquíes.

\section{TRÁFICO ILEGAL DE DROGASTÓXICAS Y ESTUPEFACIENTES}

En todos los análisis internacionales acerca de los conflictos existentes entre España y Marruecos, propiciados por su vecindad, suele repetirse el factor relativo al tráfico ilegal de drogas tóxicas y estupefacientes. 


\subsection{La situación en África Occidental}

Europol señala en su análisis anual sobre el crimen organizado y sus amenazas (2011):

- El punto principal de entrada de hachís en la UE es la costa meridional española, adonde llega desde los países africanos occidentales y, principalmente, desde Marruecos, Nigeria, Cabo Verde y Senegal por el corredor criminal del Sudoeste (SouthWest criminal hub),$^{14}$ que además enlaza con América (islas del Caribe), Oriente Próximo (El Líbano) y Asia (Tailandia). En particular, la mayoría del hachís consumido en la UE proviene de Marruecos, desde donde es dirigido principalmente a España y Portugal mediante la acción de grupos criminales no sólo marroquíes, sino también holandeses y británicos que coordinan su llegada al centro de distribución criminal del noroeste (North West criminal hub $)^{15}$ y, desde este o directamente, a Alemania, Reino Unido, Italia y países nórdicos; en los puntos finales la distribución al por menor (menudeo) se realiza principalmente por marroquíes. Por otro lado, el hachís marroquí está alcanzando más países de destino mediante la tapadera del transporte marítimo en contenedores, sobrepasando el South West criminal hub. ${ }^{16}$ Se ha observado además el uso creciente del avión ligero en envíos a la península ibérica. Adicionalmente, se registran envíos a través de otros países norteafricanos, en especial recurriendo a las rutas existentes y grupos criminales activos para otros tipos de delincuencia, como el tráfico ilegal de migrantes.

- En cuanto a la cocaína, Europol afirma que los grupos marroquíes conservan su posición dominante en el tráfico desde el Oeste de África, enlazando con la ruta establecida en el norte de dicho continente para el hachís. Además, la inestabilidad política en países tales como Costa de Marfil constituye un riesgo para el aumento a largo plazo de las actividades criminales en el África occidental y, en particular, para el trasbordo de cocaína hacia la UE.

${ }^{14}$ Según Europol, los Hubs criminales son concentraciones de logística criminal que reciben flujos ilícitos de fuentes numerosas, y cuya influencia se extiende a través de la UE. Tales concentraciones facilitan no sólo traficar con materias ilícitas, sino también la creación de nuevos mercados delictivos, proporcionando nuevas oportunidades para los grupos criminales. La identificación de los hubs se basa en su proximidad a los más importantes mercados e infraestructuras comerciales y de transporte, así como en el predominio de grupos criminales y en las oportunidades para la actuación delictiva. Entre los hubs identificados está el del Sudoeste, cuyo centro de gravedad lo conforman España y Portugal.

${ }^{15}$ Ibídem.

${ }^{16}$ Ibídem. 
- Sobre el tráfico de heroína, Europol indica que, según informaciones obtenidas del crimen organizado turco en Marruecos, este país puede alcanzar una mayor importancia en el futuro dentro del SouthWest criminal hub. ${ }^{17}$

- Como uno de los efectos delictivos añadidos, se hace constar que algunos grupos de traficantes marroquíes de hachís hacia la península ibérica, cooperan con grupos criminales italianos dedicados a la falsificación de euros.

- De cara al futuro, destaca la tendencia de las organizaciones de tráfico ilegal a aprovechar para sus actividades el incremento progresivo de las zonas de libre cambio (Free Trade Zones) y del tráfico marítimo de contenedores (en especial Tánger).

\subsection{La situación en Marruecos}

La CIA indica textualmente:"[Marruecos es] uno de los mayores productores de hachís ilegal; de embarques de hachís expedidos generalmente a Europa Occidental; punto de tránsito para la cocaína procedente de Sudamérica y destinada a Europa Occidental; consumidor significativo de cannabis". ${ }^{18}$ En rigor no debe olvidarse, empero, que la misma fuente cita textualmente en el caso de España las facilidades aportadas al tráfico de drogas por la gran extensión de la línea costera española: "A pesar de los rigurosos esfuerzos para la aplicación de la ley, los traficantes norteafricanos [...] se aprovechan de la larga línea de costa española para lanzar grandes envíos de [...] hachís para su distribución al mercado europeo, para los consumidores de $[\ldots]$ hachís norteafricano $[\ldots]]^{19}$

En cuanto a otras fuentes de solvencia, el Análisis Anual de Riesgos publicado por FRONTEX ${ }^{20}$ (2011), señala que el contrabando de hachís puede constituir el objetivo principal de algunas embarcaciones marroquíes que, dedicadas aparentemente al tráfico de migrantes, llegan a España con muy pocas personas a bordo.

Por su parte, determinadas investigaciones ${ }^{21}$ constatan que: a) Marruecos es el mayor productor-exportador mundial de hachís, aportando el 70\% del producto que se consume en Europa y el 50\% de la producción mundial; b) 750.000 campesinos de las

\footnotetext{
${ }^{17}$ Ibídem.

${ }^{18}$ The World Factbook (2011) - Central Intelligence Agency (CIA). Traducción del autor.

${ }^{19}$ Ibídem.

${ }^{20}$ Agencia europea para la gerencia de la cooperación operativa en las fronteras externas de los Estados miembros de la Unión Europea.

${ }^{21}$ GAMELLA, J. F. (Universidad de Granada, 2009) y JIMÉNEZ RODRIGO, M. L. (Universidad de Sevilla, 2009)
} 
provincias del Rif vivirían de los correspondientes cultivos; c) El año con más alta producción de hachís fue 2003, reduciéndose hasta ahora tanto por la sequía sobrevenida como por la presión gubernamental.

El escenario regresivo y una de las causas que lo propician es confirmado por las autoridades marroquíes, ${ }^{22}$ quienes cuantifican la reducción de la superficie cultivada de cannabis en un 55\% en los últimos años para los que existen datos fiables; en efecto, se constata que se ha producido un descenso dese 134.000 ha en 2003 hasta 56.000 en 2009 y que, en correspondencia, la producción de resina de cannabis descendió de 3.070 tm a 820 en el mismo período.

Las cifras anteriores se revalidan en el informe sobre 2010 del Organismo Internacional de Control de Estupefacientes (OICE) dependiente de la ONU, lo que refuerza la constatación de resultados positivos de la estrategia gubernamental marroquí comenzada al efecto en 2003. En continuidad con ella, el 16.05.2009 se lanzó un nuevo programa interministerial (Interior, Agricultura y Hábitat y Urbanismo) con las siguientes características: a) Se prevé el fomento de cultivos alternativos, la creación de nuevas actividades generadoras de ingresos, el desarrollo de infraestructuras de carreteras y el impulso de servicios sociales; ${ }^{23}$ b) Su horizonte temporal es de dos años y su dotación económica de 900 millones de dírhams (80 millones de euros); c) Beneficiará a 74 municipios (12,1 millones de dírhams ó 1,08 millones de euros para cada uno), repartidos entre las provincias rifeñas de mayor producción de hachís: Alhucemas, Chefchauen, Taunate, Larache y Tetuán. Debe añadirse que Marruecos recibe ayudas económicas de la UE para esta finalidad.

Por otra parte, el Departamento de Estado norteamericano en su último informe sobre la estrategia de lucha contra las drogas en el mundo, hecho público en Washington (2011), pronostica el éxito de la estrategia antidroga marroquí, apoyada por cultivos de sustitución dentro de un amplio enfoque de desarrollo económico, y por unos 10.000 agentes del orden desplegados exprofeso, junto a fuerzas de la Marina Real, en las zonas costeras del norte y del suroeste del reino. Dicho informe es optimista sobre los objetivos de Marruecos de reducir drásticamente el cultivo global de cannabis, desde un nivel actual estimado en 50.000 ha a 12.000 en 2012.

${ }^{22}$ BENMUSA, Ch., Ministro del Interior; Agencia oficial MAP; Diario de Tánger; edición electrónica del 18.05.2009: <http://www. diariotanger.com>.

${ }^{23}$ Principalmente los de abastecimiento de agua potable y suministro de electricidad, formación profesional y sanidad. 


\subsection{Efectos para la seguridad de Melilla}

En tanto no se erradique la situación actual, es evidente que también por esta vía se introducen factores de riesgo, junto a sus correlativas amenazas, en las relaciones hispanomarroquíes. En principio no en lo que respecta a las de carácter oficial (sometidas al imperio de la ley), sino a las de carácter privado y a sus efectos, especialmente en lo que se refiere al florecimiento de una economía sumergida, no productiva, redistribuidora de la renta en un sentido negativo, distorsionadora de la libre competencia y, en consecuencia, causante de una base económica volátil, regresiva y decididamente perniciosa en el hinterland de Melilla y Ceuta.

Por último debe tenerse en cuenta el contagio que toda actividad delictiva, en este caso el tráfico ilegal de drogas tóxicas y estupefacientes, así como las actividades que surgen a su alrededor (como entre otras la antes indicada de falsificación de moneda), son susceptibles de provocar en su entorno geográfico.

\section{INMIGRACIÓN CLANDESTINA}

En todos los análisis internacionales acerca de los conflictos existentes entre España y Marruecos, se repite más o menos la misma advertencia: "Marruecos constituye una de las áreas primarias de lanzamiento de inmigración ilegal al interior de España desde el Norte de África" (CIA, 2011). ${ }^{24}$ En cuanto a la composición de dicha inmigración debe precisarse que, si bien siempre ha existido (en límites escasamente significativos) inmigración ilegal originaria de Marruecos, ${ }^{25}$ desde 1993 comenzó a ampliarse con otra cuyo origen era subsahariano, en sus inicios, más asiática posteriormente. ${ }^{26}$

${ }^{24}$ The World Factbook (2011) - Central Intelligence Agency (CIA). Traducción del autor.

${ }^{25}$ La inmigración procedente del propio Marruecos encuentra múltiples facilidades: condiciones favorables para la recepción de emisiones de las televisiones españolas y occidentales en general -incluida la profusión de antenas parabólicas - con unas programaciones que exaltan el consumismo, facilidad con que se puede efectuar el viaje, y facilidades idiomáticas y culturales heredadas de la época del Protectorado.

${ }^{26}$ Según el Consejero de Trabajo de la Embajada de España en Rabat (Eduardo Martín Toval), entre 2004 y 2007 la UE envió a Marruecos un total de 100 millones de euros para el refuerzo policial de sus fronteras. 


\subsection{Detecciones, factores de atracción y pronósticos}

El Ministerio del Interior español respondía a determinada interpelación parlamentaria, informando que los inmigrantes ilegales interceptados en Melilla por los CFSE fueron, en el período 2004-2008, los siguientes: 353 en 2004, 571 en 2005, 239 en 2006, 212 en 2007 y 1.201 en 2008. Sin embargo, tales cifras no deben ocultar que en Marruecos y los países próximos (Argelia y, sobre todo, Libia) se estima que residen (legal o ilegalmente y temporal o definitivamente) en torno a dos millones de subsaharianos, más un número indeterminado de asiáticos; su incremento anual oscilaría entre 70.000 y 80.000 personas. $^{27}$

Según el informe anual de FRONTEX (2011) España fue en 2010 el segundo Estado miembro de la UE (tras Grecia) por entradas ilegales, con un 5\% del total, lo que supone en torno a las 5.000 detecciones; de estas, 3.5000 (el 70\%) corresponden a Ceuta y Melilla, y el resto a las costas peninsulares. Estas ciudades constituyen el eslabón final de la ruta del Mediterráneo occidental (Western African route), cuyo último escalón es el cruce marítimo hacia el continente europeo; dicha ruta, una de las tres identificadas para el acceso a la UE desde África, es la elegida por la mayoría de los emigrantes marroquíes y argelinos.

El citado informe señala por otra parte que en España sigue produciéndose un importante descenso de las inmigraciones ilegales. Sobre la escasa operatividad actual de la ruta africana citada, indica que una de las razones principales es que la cooperación y los acuerdos bilaterales entre España y los países africanos occidentales dominantes (Mauritania, Senegal, Malí) continúan desarrollándose constantemente; aparte de la presencia de patrullas marítimas costeras. Como ejemplo, las 196 travesías fronterizas ilegales detectadas en 2010 en Canarias, contrastan con las 2.244 registradas en 2009. Este contexto, de retraimiento en la zona de la actuación de los grandes grupos criminales de tráfico de inmigrantes, es coherente con las recientes detecciones de métodos cuasi artesanales, como es el caso del sky acuático (jet skis) y de los botes inflables (inflatable dinghies) entre Marruecos y la costa sur española. En lo que respecta a la valla fronteriza entre Melilla y Nador, en 2010 sólo constan unos pocos incidentes.

Un factor clavede atracción de inmigración a tener en cuenta, con relación especialmente a la de origen magrebí, es la diferencia de renta entre España y Marruecos en general, y entre Melilla y su hinterland marroquí en particular. En efecto, en 2001 el

\footnotetext{
${ }^{27}$ PÉREZ, A. (2005)
} 
PIB per cápita español multiplicaba por 12'6 el marroquí (por 5'5 en paridad de poder adquisitivo o PPA), mientras que la media para las más de 180 fronteras del mundo se situaba, según el Banco Mundial, en 3'5 (en 2'2 en PPA). Entre todas esas fronteras la de España-Marruecos ocupaba, de mayor a menor escalón, el puesto noveno (el octavo en PPA), si bien era la segunda en la que participaba un país europeo, tras la de FinlandiaRusia y por delante de la de Grecia-Albania (en PPA era sin embargo la primera, por delante de Rusia-Mongolia). En 2010, la estimación del PIB per cápita español en PPA lo situaba en 29.500 \$, mientras que en el caso de Marruecos en tan sólo $4.900 \$ ;^{28}$ ello implica un escalón económico entre ambos países de 6’0 veces el PIB per cápita en PPA. Y ello sin olvidar que el multiplicador se aproximará más al nominal, estimado para el mismo año en 10'3, cuanto más bienes y servicios adquieran en Marruecos los españoles y más bienes y servicios adquieran en España los marroquíes, lo que alcanza su punto máximo, por la proximidad, en el caso de melillenses y nadorenses.

En lo que respecta a los enfrentamientos internos en Libia y a sus repercusiones, la Organización Internacional para las Migraciones (OIM) estima que el mayor grupo de potenciales emigrantes, los trabajadores extranjeros en dicho país, oscilaría entre 0' 5 y 1'5 millones, aunque no todos tendrían como objetivo el destino Europa. Sobre los efectos potenciales de una imposición de emigración a dicho grupo por el régimen de Gadafi, FRONTEX (2011) incluye a España entre los países que se verían afectados. Estima además que los escenarios a considerar son varios: según quien gane el conflicto actual, según cuál sea su reacción y según en qué tiempo es adoptada; en el peor de los casos, dado que Libia cuenta con $2.000 \mathrm{~km}$ de costas y $4.000 \mathrm{~km}$ de fronteras terrestres, así como considerando la numerosa población afectada, la evolución podría empeorar hasta una situación análoga a la de Somalia. ${ }^{29}$

Por añadidura, en el caso de que las repercusiones libias provocaran una desestabilización de Marruecos, el director general adjunto de FRONTEX (ARIAS, 2011) considera que los traficantes de inmigrantes reactivarían los canales orientados hacia la UE, incluido "el cruce de las fronteras terrestres con Ceuta y Melilla"; la afluencia sería no sólo de ciudadanos magrebíes sino también subsaharianos y asiáticos, a los que se sumarían los que acampan ocultos en las proximidades de ambas ciudades. Sobre estas "se reproducirían los ataques masivos a las vallas fronterizas como los acaecidos en 2005”.

\footnotetext{
${ }^{28}$ The World Factbook (18.04.2011) - Central Intelligence Agency (CIA).

${ }^{29}$ Según ARIAS, G. (2011), entre el comienzo del conflicto en Libia y el 10 de marzo de 2011, han huido del país más de 200.000 personas, la mayoría trabajadores extranjeros que han regresado a sus países de origen o tratan de hacerlo, a través de Egipto y Túnez principalmente.
} 
En cuanto a las posibilidades de absorción de Melilla, el Centro de Estancia Temporal de Inmigrantes (CETI), cuyo funcionamiento se inició en 1999, cuenta oficialmente con una capacidad de acogida de 472 plazas (512 el de Ceuta). Presta a los inmigrantes y solicitantes de asilo servicios de primera acogida y prestaciones sociales básicas: alojamiento y manutención, atención social, atención psicológica, atención sanitaria, asesoramiento legal, formación, ocio y gestión del tiempo libre. ${ }^{30}$ La estancia temporal no termina siempre, como se sabe, con la devolución de los inmigrantes a sus respectivos países, sino que dadas las dificultades para conseguirlo el destino de muchos de ellos acaba siendo su traslado a la Península; esto con el fin de evitar saturaciones del CETI que colapsen los sucesivos flujos de entrada, y a pesar de la instalación adicional en caso necesario de tiendas de campaña homologadas que amplíen las plazas disponibles. La imposibilidad práctica de superar la dinámica descrita, contribuye inexorablemente a un efecto llamada capitalizado por las organizaciones criminales de tráfico de personas.

No puede finalizarse este apartado sin hacer alusión a un factor que, en los últimos años, es contrario a la llegada a Europa de inmigración ilegal. Radica en uno de los efectos generados por la crisis económica global y que en España alcanza la máxima virulencia: la fuerte caída del empleo en los sectores, actividades y ocupaciones más demandados habitualmente por los inmigrantes clandestinos. ${ }^{31}$

\subsection{Efectos para la seguridad de Melilla}

El objetivo de todas las personas subsaharianas y asiáticas citadas, además de determinados magrebíes del entorno, está claro que radica en entrar en territorio comunitario a través de Melilla o de Ceuta. ${ }^{32}$

En tal contexto resulta evidente que, dada la reducida dimensión territorial y poblacional de dichas ciudades (en el caso de Melilla 12,4 km² y 76.034 habitantes en 2010),,$^{33}$ la amenaza de los flujos futuros de inmigrantes ilegales comporta un grave elemento de riesgo para la vida cotidiana en las mismas tal como la conocemos hasta ahora (el momento álgido fue alcanzado entre octubre y noviembre de 2005).

\footnotetext{
${ }^{30} \mathrm{http}: / /$ www.mtin.es/es/guia/texto/guia_8/contenidos/guia_8_22_4.htm

${ }^{31}$ PAPADEMETRIOU, D. G. y otros (2010).

${ }^{32}$ Y ello sin perjuicio de alternativas tales como la de intentar la vía de Malta, o la de determinados territorios insulares de Italia o Francia.

33 INE (2011).
} 
El citado riesgo puede ser agravado mediante determinadas actuaciones de Marruecos. Una de ellas podría ser el endurecimiento de, o la negativa a, la aceptación de los flujos de repatriaciones hacia Marruecos a través de las fronteras con Melilla y Ceuta, en función de la nacionalidad de los repatriados o de otros criterios más o menos caprichosos. ${ }^{34}$ Otra actuación podría consistir en una laxitud en el control fronterizo del paso clandestino de inmigrantes subsaharianos y asiáticos a Melilla y Ceuta. No se trata necesariamente de actuaciones marroquíes probables, pero sí posibles en un eventual marco de escalada de tensiones con España y de adopción de medidas de presión.

\section{AUGE DEL ISLAMISMO RADICAL VIOLENTO}

A raíz de los atentados terroristas del 11-S 2001 en Nueva York, el terrorismo islámico internacional se convierte en Occidente en el paradigma de la materialización del choque de civilizaciones de Samuel HUNTINGTON (1993) y las consideraciones económicas sobre mercados y producción abandonan el primer plano de las tensiones internacionales. Para España dicha tendencia se refuerza con el atentado del 16-M 2003 en Casablanca y con el del 11-M 2004 en Madrid.

\subsection{Presencia en Marruecos}

La situación actual en Marruecos del islamismo radical o integrista, ${ }^{35}$ se manifiesta en los tres niveles siguientes: a) El primero, la corriente salafista estructurada en forma de asociación a través de una red de más de cien centros coránicos, repartidos por más de treinta ciudades del país; b) Un segundo nivel, integrado por una serie de pequeños grupos de carácter violento que, amparados en la doctrina salafista y en la "Yihad", cometen actos

${ }^{34} Y$ ello a pesar de que tanto España como Marruecos están entre los 122 miembros de la 'Organización Internacional para las Migraciones (IOM), establecida el 5 de diciembre de 1951 y cuya finalidad es facilitar una emigración e inmigración internacionales ordenadas.

${ }^{35}$ Se caracteriza por preconizar la violencia aprovechando el discurso religioso, desarrollar sus actividades cotidianas dentro de una relativa clandestinidad, contar con una red asociativa diversa, carecer de estructuras sólidas -con la excepción de la corriente salafista-, evitar la predicación en las mezquitas públicas -de las casi 32.000 mezquitas existentes en Marruecos, tan sólo 8.659 dependen de la Administración-, extraer la mayoría de sus seguidores de las capas de población marginal de los populosos suburbios urbanos, y escapar generalmente a la rigurosa vigilancia a que el Majzén somete a la religión en Marruecos. 
vandálicos y delictivos; c) Un tercer nivel, formado por dos corrientes violentas, una supuestamente conectada a la organización terrorista Al-Qaeda, y otra compuesta por pequeños grupos, de estructura y contenido muy cambiantes en función del surgimiento de nuevas interpretaciones religiosas de determinados clérigos. Esta última corriente se considera la más peligrosa, hasta el punto de que podría ocuparse de la recluta de terroristas para el Grupo Islámico Combatiente Marroquí (GICM). ${ }^{36}$

Debe destacarse en este contexto la cooperación judicial antiterrorista entre los reinos de España y Marruecos, la cual está constituyendo un factor clave en la lucha contra el terrorismo internacional y que se acompaña de la intensa actividad diplomática desplegada por España en dicho país en las áreas comercial, cultural, de cooperación al desarrollo, económica, educativa, financiera, militar, policial, política y social. ${ }^{37}$

\subsection{Riesgos para Melilla}

Las amenazas que el citado islamismo comporta para la seguridad de España, se concretan en función del área geográfica, ya sea dentro del país, ya sea fuera, pero en ambos casos con la finalidad de, bien actuar contra intereses españoles directamente, bien generar tensiones que permitan la consecución de ciertos objetivos. Dentro del territorio nacional debe considerarse a su vez la coexistencia de dos escenarios: por una parte, la formación de células terroristas, cuya realidad ya ha sido confirmada por los hechos; ${ }^{38}$ por otro lado, el control y reclutamiento de potenciales terroristas entre la población inmigrante musulmana, aprovechando la asistencia multitudinaria a mezquitas y centros coránicos. La propia Fiscalía General del Estado ha alertado en sus últimos informes anuales del riesgo de atentados islamistas en España.

En lo que respecta a las amenazas del terrorismo islámico contra intereses españoles en el extranjero, se constata que los dos atentados islamistas más graves se produjeron en Marruecos: en 1994 contra un grupo de turistas españoles en Marrakech, y en 2003 en

\footnotetext{
${ }^{36}$ Creado el año 2002 en Londres y que en una reunión mantenida en 2003 por su fundador - el inmigrante marroquí Mohamed Guerbouz- con algunos miembros de Al-Qaeda en Estambul, habría adoptado la decisión de desencadenar la "Yihad" en Marruecos.

${ }^{37}$ LLORENTE, A. (2010).

${ }^{38}$ Recuérdense los dos sangrientos atentados producidos en Madrid, el primero en los años ochenta del siglo pasado y el último en 2004; la detención en España de marroquíes implicados en los atentados de Septiembre de 2001 en Nueva York; la desactivación de algunas células de apoyo islamista; y las detenciones de terroristas del GIA argelino.
} 
Casablanca, donde murieron más de cuarenta personas y cuyos objetivos se considera que fueron seleccionados principalmente entre los intereses israelíes y españoles. ${ }^{39}$ Además, en tanto en cuanto los objetivos de los atentados son los propios ciudadanos españoles, surge la preocupación ante una posible alianza entre islamismo radical violento y nacionalismo extremista.

La posible alianza islamismo-nacionalismo acabada de citar, que por parte nacionalista podría incubarse en el Partido Liberal Reformador (PLR), ${ }^{40}$ resultaría especialmente grave para Melilla. En efecto, hay analistas que consideran que "Nada impide pensar que pudieran crearse otros grupos armados para actuar en España, en concreto en aquellos territorios que, por ser fronterizos, parecen más vulnerables como es el caso de Ceuta y Melilla”. ${ }^{41}$ Incluso hay quien se plantea un escenario futuro de posible conexión entre las instituciones políticas marroquíes y el islamismo, habida cuenta que éste "es mayoritario en el país y será necesario e inevitable un pacto entre la monarquía y el mismo a medio plazo". Por último, cabe recordar las reiteradas amenazas expresas contra Melilla y Ceuta realizadas por dirigentes de Al-Qaeda en la televisión Al-Yazira y en otros medios de comunicación de difusión internacional.

\section{CONCLUSIONES}

Las conclusiones que procede formular sobre la base del trabajo desarrollado son las siguientes:

\section{$1^{\mathrm{a}}$. Contencioso internacional del Sahara Occidental}

a) Marruecos podría amagar con la reactivación y escalada de sus demandas sobre Melilla, como elemento de presión para obtener el apoyo activo de España en las propuestas para solucionar el contencioso internacional sobre el antiguo Sahara Español.

b) Una vez solucionado el diferendo del Sahara Occidental, Marruecos podría intentar proseguir la expansión geográfica que caracteriza a la dinastía alauita,

${ }^{39}$ Sobre el atentado del 28 de abril de 2011 en Marrakech, localizado en un establecimiento turístico y que produjo 16 víctimas mortales, se carece por el momento de información fidedigna sobre su autoría, objetivos y demás características.

${ }^{40}$ Creador del Frente para la Liberación de la Argelia Marroquí (FLAM)

${ }^{41}$ PÉREZ GONZÁLEZ, M. R. (2004) 
procediendo a la reactivación y escalada sostenida de sus demandas sobre Melilla y los demás territorios españoles situados geográficamente en el continente africano.

\section{$2^{a}$. Pesca española en caladeros marroquíes}

a) La prórroga del acuerdo de pesca UE-Marruecos 2007-2011, no soluciona de cara al futuro las tensiones hispano-marroquíes en torno a la pesca en caladeros marroquies'por barcos españoles; simplemente las difieren hasta después del 27.08.2011 (o incluso antes si el Consejo o el Parlamento europeos rechazan la aún pendiente ratificación de la prórroga).

b) A medida que se acerque la citada fecha, son de pronosticar reticencias para otra prórroga, así como para un nuevo acuerdo, por parte de los países que se opusieron a la prórroga en vigor sobre la base de conectar este asunto con el del Sáhara Occidental, en el sentido de oponerse a la inclusión en el acuerdo de los caladeros saharauis. Si se llega a este punto, Marruecos podría recurrir a las mismas acciones descritas en la conclusión $1^{\mathrm{a}}$. a).

\section{$3^{a}$. Tráfico ilegal de drogas tóxicas y estupefacientes}

a) La actividad delictiva desarrollada en Marruecos en torno al tráfico de hachís y otras drogas de intercambio no autóctonas, extiende su radio de acción a Melilla, con lo que impulsa una actividad criminal de la misma tipología en esta ciudad. Simultáneamente se produce una presión de contagio sobre el resto de la criminalidad asociada a las drogas tóxicas y estupefacientes.

b) Las actividades delictivas resultantes originan efectos negativos sobre la actividad económica y social de Melilla, en especial los de movilización de fondos procedentes del narcotráfico. Estos tienden a introducirse en los circuitos financieros de determinadas empresas,"constituyendo la base de una competencia ilícita que puede expulsar del mercado, con carácter irreversible, a aquellas de las empresas competidoras que sí operan dentro de la ley.

\section{$4^{a}$. Inmigración clandestina}

a) Se constata el riesgo de que la inmigración de origen y procedencia magrebí que afectaba inicialmente a Melilla (marroquí y argelina fundamentalmente), así como las de origen subsahariano y asiático que se sumaron posteriormente, se reactiven y amplifiquen como consecuencia de la "Revolución de los jazmines en Túnez” y de sus secuelas en los países norteafricanos de nuestro entorno. 
b) Por otra parte, no puede obviarse que Marruecos podría, en el marco de una escalada de tensiones con España por cualquiera de los diferendos abiertos (Sáhara, Melilla y Ceuta, etc.), utilizar medidas de presión en el ámbito de la inmigración. Sería el caso, entre otros, de la negativa a aceptar determinadas repatriaciones de marroquíes (en general o por las fronteras terrestres de Melilla y Ceuta), o el facilitar, o bien no oponer medida alguna en contra, el acceso a Melilla (y Ceuta) de los grandes grupos de migrantes subsaharianos y asiáticos que se desplazan por el norte de África. A estos grupos podrían agregarse los procedentes de Libia y otros países afectados por el cambio social iniciado en Túnez.

\section{$5^{a}$. Auge del islamismo radical violento}

a) La amenaza que supone para España la evolución del islamismo radical violento, alcanza su grado máximo en el caso de Melilla y Ceuta en tanto concurren los dos factores siguientes: por una parte, su situación limítrofe con Marruecos, que incluye la única frontera terrestre entre un país europeo y el Magreb (por la que transita diariamente un flujo aproximado de 30.000 personas y 5.000 automóviles); por otro lado, están las amenazas expresas contra ambas ciudades efectuadas en la televisión Al-Yazira por el lugarteniente en Al-Qaeda del desaparecido Bin Laden.

b) Los riesgos derivados de la amenaza acabada de citar implican tanto la posibilidad de la formación interna de células terroristas, particularmente mediante la recluta de extremistas violentos efectuada en lugares de reunión pública y asociaciones diversas, como la utilización de terroristas captados en el exterior a quienes se facilitaría una cobertura de entrada en España. Este último riesgo de origen internacional, enlaza con el hecho de que el proselitismo terrorista en Marruecos se ve facilitado, teóricamente, por la existencia de un centenar de centros coránicos y unas 32.000 mezquitas, de las cuales no llegan a 9.000 las que cuentan con el control inherente a su dependencia de la Administración pública.

\section{BIBLIOGRAFÍA}

AGUILAR, M. A. [Periodista] «El abandono del Sáhara». Madrid: El País, 2010 [16 de noviembre], p. 11.

ALMAZÁN, J. L. "2ª Jornada sobre Desarrollo y Seguridad en el Mediterráneo”. Jornadas 
sobre Desarrollo y Seguridad en el Mediterráneo. Melilla: Autoridad Portuaria, 2009 [23 de abril].

AMIRAH-FERNÁNDEZ, H. "Hacia un cambio de paradigma en las relaciones euromediterráneas”. ARI, n ${ }^{\circ}$ 76. Madrid: Real Instituto Elcano, 2011 [27 de abril]. "Las relaciones de Estados Unidos con el Magreb». Culturas, n. ${ }^{\circ}$ 4, [Monografía «Estados Unidos y Oriente Próximo»]. Sevilla: Fundación Tres Culturas, 2009 [mayo], p. 72-79.

ARAHUETES. A.; STEINBERG, F. «IV Índice de riesgos y oportunidades del Real Instituto Elcano». Madrid: Real Instituto Elcano, 2010.

ARIAS, G. "La crisis en el Norte de África y su impacto en la inmigración irregular a la Unión Europea”. ARI, n 87. Madrid: Real Instituto Elcano, 2011 [9 de mayo].

ARIAS, I. F. [Diplomático, representó a España ante la ONU] «Sorpresas del Sahara Occidental». Madrid: El Mundo, 2010 [9 de noviembre], p. 30.

AVILÉS, J. «El impacto de la inmigración sobre la seguridad ciudadana”. ARI, Área: Demografía, Población y Migraciones Internacionales. Madrid: Real Instituto Elcano, 2008 [1 de diciembre], n. ${ }^{\circ} 155$.

AZIZA, M. La sociedad rifeña frente al protectorado español en Marruecos. Barcelona: Bellaterra, 2003.

"La frontière de Nador-Melilla, une frontière européenne en terre marocaine. Analyse des relations transfrontalières". [Comunicación presentada en el seminario] Le Rio Bravo Méditerranéen: les régions frontalières à l'heure de la mondialisation. [s.l.]: [s.n.], 2006.

BENYAHIA, A.: "El diálogo euromediterráneo y los conflictos regionales". ARI. Área: Mediterráneo y Mundo Árabe. Madrid: Real Instituto Elcano, 2003 [22 de abril], n. ${ }^{\circ} 63$.

BENANTAR, A. «La démocratisation des États arabes redéfinira le dialogue de sécurité en Méditerranée». Notes Internacionals CIDOB, no 29 [Université Paris 8]. París: CIDOB, 2011 [abril]. E-ISSN: 2013-4428.

BUJARI, A. [Representante del Frente Polisario ante la ONU] «El Sahara y la seguridad de España». Madrid: El País, 2010 [12 de febrero], p. 27.

CAJAL, M. [Embajador de España] «El Sahara y la razón de Estado». Madrid: El País. 2010 [11 de enero], p. 29.

CAPELLA SOLER, R. «Los derechos humanos, ¿un obstáculo para la paz en el Sáhara Occidental?”. ARI, n 47. Madrid: Real Instituto Elcano, 2011 [8 de marzo].

CEMBRERO SILVERO, I. «Bronca en la ONU sobre el Sáhara Occidental». Madrid: El País, 2011 [15 de abril], p. 2. 
_ Vecinos alejados. Los secretos de la crisis entre España y Marruecos. Barcelona: Galaxia Gutenberg-Círculo de Lectores, 2006. ISBN 84-672-1669-7

DE CUETO NOGUERAS, C. "Seguridad y diversidad en las sociedades contemporáneas". (Coord.). [s.l]: Biblioteca Nueva, 2005. ISBN 84-9742-388-7.

DE LA SERNA, A. Al sur de Tarifa. Marruecos-España: un malentendido histórico. Madrid: Marcial Pons, 2001.

DE PINIÉS BIANCHI, J. [Economista] «España, responsable de la descolonización». Madrid: El Mundo, 2010 [19 de noviembre], p. 27.

DELMOTE, G. Ponts et frontières entre l'Espagne et Maghreb. París: L'Harmattan [Histoire et Perspectives Mediterranéennes], 2001.

ECHEVERRÍA JeSÚS, C.: "Las Políticas de Seguridad y de Defensa de los Países del Magreb”. Documento de Trabajo, n. ${ }^{\circ}$ 11. Madrid: Real Instituto Elcano, 2005 [3 de marzo].

ESPAÑA. MINISTERIO DE DEFENSA. Política de Defensa en el Mediterráneo. Iniciativas de Seguridad. [s.l.]: [s.n.], 2005 [2 de noviembre].ESTADOS UNIDOS. CENTRAL INTELLIGENCEAGENCY (CIA). TheWorld Factbook. Disponible enWeb (2011): < https: / /www.cia.gov/library/publications/the-world-factbook/appendix/appendix-a.html>

FERRER-GALLARDO, X. Theorizing the Spanish-Moroccan Border Reconfiguration: Framing a Process of Geopolitical, Functional and Symbolic Rebordering. CIBR Working Papers in Border Studies. WPO6-1. 2006.

FIBLA, C. España-Marruecos desde la orilla sur. La relación hispano-marroquí: opiniones e ideas. Barcelona: Icaria Antrazyt, 2005.

GARCÍ́A AYALA, J. A. Melilla y sus primeros 25 años en la Unión Europea (1986-2011). Situación y perspectivas de instrumentación económica y social de las políticas comunitarias. Melilla: GEEPP, 2011. [422 p.]. ISBN 978-84-92850-42-6. Las políticas de la Unión Europea en Melilla (1986-2008):Valoración de sus efectos, prospectiva y decisiones estratégicas para su optimización desde una perspectiva de seguridad económica y social. Tesis doctoral. Granada; Melilla: Universidad de Granada, 2009. Disponible en web: <http:// hera.ugr.es/tesisugr/18604985.pdf>

_ Planteamiento de la problemática de seguridad y defensa en la región mediterránea: Estado de situación en 2006. [Cursos de Doctorado en la Universidad de Granada. Período de docencia]. Melilla: (en prensa), $64 \mathrm{p}$.

GOLD, P. "Immigration into the European Union via the Spanish Enclaves of Ceuta and Melilla: A Reflection of Regional Economic Disparites". Mediterranean Politics. [s.l.]: [s.n.], 1999, n. ${ }^{\circ} 4$ (3), p. 23-36. 
GONZÁLEZ ENRÍQUEZ, C. «Los cambios políticos y las migraciones desde los países árabes". ARI, n 60. Madrid: Real Instituto Elcano, 2011 [24 de marzo].

GONZÁLEZ ENRÍQUEZ, C; PÉREZ GONZÁLEZ,A. “Ceuta y Melilla: nuevos elementos en el escenario”. ARI, Área: Demografía y Población. Madrid: Real Instituto Elcano, 2008 [4 de diciembre], n. ${ }^{\circ} 159$.

GRUPO DE ESTUDIOS ESTRATÉGICOS. "Marruecos aliado preferencial de Estados Unidos”. Revista Grupo de Estudios Estratégicos GEES. [s.l.]: [s.n.], 2004 [25 de junio], nota . $^{\circ} 16$.

HAJJAJI, T. Le phénomene de la contrebande au Maroc. Memoire du Cycle superieur. Rabat: École nationale de l'administration publique, 1986.

HERNANDO DE LARRAMENDI, M. "Las relaciones hispano-marroquíes durante los años noventa”. Atlas de la inmigración marroquí en España. Madrid: Universidad Autónoma, 2004.

HUNTINGTON, S. "The Clash of Civilizations?", Foreign Affairs, 1993, vol. 72, n 3, p. 22-49.

HERNANDO DE LARRAMENDI, M.; PLANET, A. «Maroc-Espagne: la crise de l'îlot du Persil». Notes et'Études Documentaires. [s.l.]: [s.n.], 2003, n. ${ }^{\circ}$ 5177, p. 133-140.

JERCH, M.; ESCRIBANO, G.; LORCA, A. «The Impact of Migration from the Mediterranean on European Security». [VASCONCELOS, A. (coord.)] A European Strategic Concept for the Mediterranean, Lumiar Papers. Lisboa: IEEI, 2002, n. ${ }^{\circ} 9$.

JOLY, D. “Les immigrés en France et en Grande-Bretagne: leçons pour l'Espagne”. ARI, Area:Demografía, Población y Migraciones Internacionales. Madrid: Real Instituto Elcano, 2008 [5 de diciembre], n. ${ }^{\circ} 160$.

JORDAN GALDUF, J. M. El Magreb en la politica de defensa española. Ceuta: Archivo Central, 2004.

KACHANI, M. «Emigración marroquí en España». Economía Exterior-L'Opinion. [s.l.]: [s.n.], 2004, n. ${ }^{\circ} 28$, p. 129-140.

KIRHLANI, S. « La salafiya: un nuevo "movimiento" en fase de gestación». Observatorio Electoral TEIM. Análisis eventual: Marruecos. Taller de Estudios Internacionales Mediterráneos - Universidad Autónoma de Madrid. Madrid: [s.n.], 2011 [2 de mayo].

LACLETA MUÑOZ, J. M. «Las fronteras de España en el mar». Documento de Trabajo, n. ${ }^{\circ}$ 34. Madrid: Real Instituto Elcano, 2004 [14 de junio].

"Las aguas españolas en la costa africana”. Revista Electrónica de Estudios Internacionales. [s.l.]: [s.n.], 2003. 
LAZRAK, R. «Le Contentieux territorial entre le Maroc et l'Espagne». Casablanca: [Dar el Kitab] Le Matin, 1974.

LMRABET, A. [Periodista marroquí] «La peor pesadilla para el rey de Marruecos». Madrid: El Mundo, 2010 [9 de noviembre], p. 30.

LÓPEZ BUENO, J. M. "Melilla: lecciones inadvertidas de integración”. ARI, Área Mediterráneo y Mundo Árabe. Madrid: Real Instituto Elcano, 2010 [20 de octubre].

LÓPEZ GARCÍA, B. «El suicidio de Marruecos». Madrid: El País, 2010 [9 de noviembre], p. 4.

«Los oriundos y el origen del conflicto del Sáhara». Madrid: El País, 2010 [29 de octubre], p. 31.

LÓPEZ GARCÍA, B.; HERNANDO DE LARRAMENDI, M. España, el mediterráneo y el mundo arabomusulmán. Diplomacia e historia. [s.l.]: Icaria-IEMed, 2011. ISBN(13): 978-84-9888-314-5

— «El Sáhara Occidental, obstáculo en la construcción magrebi”. Documento de Trabajo, n 15. Madrid: Real Instituto Elcano, 2005 [23 de marzo].

LORCA, A.; ESCRIBANO, G. "El Mediterráneo, frontera sur de la Unión Europea". [VARA, M.J.; PALAZUELOS, E. (eds.)] Grandes áreas de la economía mundial. Madrid: Ariel, 2002.

—_ Las economías del Magreb. Opciones para el siglo XXI. Madrid: Pirámide, 1998. “Geoeconomía y geopolítica mediterráneas". Revista de Economía, n. ${ }^{\circ}$ 759. [s.l.]: ICE, 1997.

MARÍN, J.M. «Una nota sobre el conflicto: conflictos para Europa desde áreas de menor renta». Revista de Economía Aplicada e Historia Económica, no 8. [s.l.]: [s.n.], 1998.

MARMOLEJO MARTÍN, J. A. "Patrón de entradas en la inmigración ilegal de la Ciudad Autónoma de Melilla”. El Estrecho de Gibraltar como espacio jurídico común. Materiales de Derecho comparado para la gestión y administración pública de asuntos fronterizos entre España y Marruecos. Valencia:Tirant Lo Blanch, 2009, p. 363-392.

MORALES LEZCANO, V. Las fronteras de la península ibérica en los siglos XVIII y XIX. Esbozo histórico de algunos conflictos franco-hispano-magrebies. Madrid: UNED, 2000.

MORÉ, I. «El escalón económico entre vecinos. El caso España Marruecos». Documento de Trabajo. Madrid: Real Instituto Elcano, 2003 [febrero].

NÚÑEZ VILLAVERDE, J. A.: "La seguridad en el Mediterráneo". Barcelona: La Vanguardia, 2001 [22 de noviembre].PAPADEMETRIOU, D. G. et al. Migration and Immigrants, Two years after the collapse: where do we stand? [s.l.]: Migration Policy Institute (MPI), 2010. 
PÉREZ GONZÁLEZ, M. R. "El islamismo en Marruecos: Riesgos y amenazas". Revista Grupo de Estudios Estratégicos (GEES), Colaboraciones, n. ${ }^{\circ}$ 185. [s.l.]: [s.n.], 2004 [5 de noviembre].

PÉREZ, A. “España-Marruecos ¿nueva crisis en el horizonte?”. Revista Grupo de Estudios Estratégicos GEES - Colaboraciones, n. ${ }^{\circ}$ 705-4. [s.l.]: [s.n.], 2005 [21 de diciembre]. POPE, H. [Director del proyecto Turquía/Chipre del International Crisis Group] «El modelo turco». Madrid: El País, 2011 [28 de marzo], p. 29.

REINARES, F. «El atentado de Marraquech y el retorno de la violencia terrorista a Marruecos». Notas de actualidad: Q\&A del Real Instituto Elcano. Madrid: RIE, 2011 [29 de abril].

_ “Mediterráneo y Terrorismo Internacional: ¿Un Nuevo Marco para la Cooperación?”. ARI, n. ${ }^{\circ}$ 149. Madrid: Real Instituto Elcano, 2005 [12 de diciembre].

RIBAS-MATEOS, N. The Mediterranean in the Age of Globalization. Migration, Welfare and Borders. New Brusnswick, NJ: Transaction Publishers, 2005.

RIDAO, J. M. [Diplomático, fue embajador de España ante la UNESCO] «Sáhara, el precio del diletantismo». Madrid: 'El País, 2010 [18 de noviembre], p. 31.

RUIZ MIGUEL, C. «Las fronteras marítimas hispano-marroquíes desde el derecho internacional». Revista Grupo de Estudios Estratégicos (GEES), Colaboraciones, n. ${ }^{\circ} 302$. [s.1.]: [s.n.], 2004].

SODDU, P. Inmigración Extra-Comunitaria en Europa: El Caso de Ceuta y Melilla. Ceuta: Archivo Central, 2002.

SZMOLKAVIDA, I. El conflicto de Perejil: la información y la opinión periodística sobre Marruecos en tiempos de crisis. Ceuta: Archivo Central, 2005.

TORREJÓN, J. D. «Las relaciones entre España y Marruecos según sus tratados internacionales». Revista electrónica de Estudios Internacionales, n. ${ }^{\circ}$ 11. [s.l.]: [s.n.], 2006.

TORTOSA, A. «Ben Laden muerto, Al Qaeda débil». [s.l.]: FP, 2011 [mayo]. UNIÓN EUROPEA. COMISIÓN. 'Plan de política en materia de migración legal. Comunicación [COM(2005) 669 final]. Bruselas: [s.n.], 2005 [21 de diciembre]. \{SEC(2005) $1680\}$

UNIÓN EUROPEA. COMISIÓN. ‘Technical Mission to Morocco.Visit to Ceuta and Melilla. On Illegal Immigration. Misión Report. [s.l.]: [s.n.], 2005 [7-11 de octubre].UNIÓN EUROPEA. EUROPOL. Europol Public Information EU Organised Crime Threat Assessment OCTA 201102 - Analysis \& Knowledge. [N. ${ }^{\circ}$ del archivo: 2530-274]. La Haya: Europol, 2011 [28 de abril] UNIÓN EUROPEA. FRONTEX. Annual Risk 
Analysis. Rfcia. $\mathrm{n}^{\circ}$ 4591. Varsovia: FRONTEX [Oficina de publicaciones de la UE], 2011 [abril]. ISBN: 978-92-95033-35-1. DOI: 10.2819/19969. <http:// www.frontex.europa.eu/situation_at_the_external_border/art23.html >

ZEGHAL, M. Islam e islamismo en Marruecos. Barcelona: Bellaterra, 2006.

ZURLO, Y. Ceuta et Melilla. Histoire, représentations et devenir de deux enclaves espagnoles. París: L'Harmattan, 2005. 